\title{
Article \\ Genetic Variability among Swine Influenza Viruses in Italy: Data Analysis of the Period 2017-2020
}

\author{
Chiara Chiapponi ${ }^{1,2, *(\mathbb{D}}$, Alice Prosperi ${ }^{1}$, Ana Moreno ${ }^{1} \mathbb{D}$, Laura Baioni ${ }^{1}$, Silvia Faccini ${ }^{1} \mathbb{D}$, Roberta $^{1}$ Manfredi ${ }^{1}$, \\ Irene Zanni ${ }^{1}$, Valentina Gabbi ${ }^{1}$, Irene Calanchi ${ }^{1}$, Alice Fusaro ${ }^{3} \mathbb{D}^{D}$, Maria Serena Beato $^{3}$, Lara Cavicchio ${ }^{3} \mathbb{D}$, \\ Camilla Torreggiani ${ }^{1}$, Giovanni Loris Alborali ${ }^{1}$ and Andrea Luppi ${ }^{1}$
}

1 OIE Reference Laboratory for Swine Influenza, Istituto Zooprofilattico Sperimentale della Lombardia e dell'Emilia Romagna (IZSLER), 25124 Brescia, Italy; alice.prosperi@izsler.it (A.P.); anamaria.morenomartin@izsler.it (A.M.); laura.baioni@izsler.it (L.B.); silvia.faccini@izsler.it (S.F.); roberta.manfredi@izsler.it (R.M.); irene.zanni@izsler.it (I.Z.); valentina.gabbi@libero.it (V.G.); irene.calanchi@izsler.it (I.C.); camilla.torreggiani@izsler.it (C.T.); giovanni.alborali@izsler.it (G.L.A.); andrea.luppi@izsler.it (A.L.)

2 Biochemistry and Molecular Biology Unit, Department of Life Sciences, University of Parma, 43124 Parma, Italy

3 Istituto Zooprofilattico Sperimentale delle Venezie (IZSVe), 35020 Legnaro, Italy; afusaro@izsvenezie.it (A.F.); msbeato@izsvenezie.it (M.S.B.); LCavicchio@izsvenezie.it (L.C.)

* Correspondence: chiara.chiapponi@izsler.it

Citation: Chiapponi, C.; Prosperi, A.; Moreno, A.; Baioni, L.; Faccini, S.; Manfredi, R.; Zanni, I.; Gabbi, V.; Calanchi, I.; Fusaro, A.; et al. Genetic Variability among Swine Influenza Viruses in Italy: Data Analysis of the Period 2017-2020. Viruses 2022, 14, 47 https://doi.org/10.3390/v14010047

Academic Editor: Elisa Crisci

Received: 25 November 2021

Accepted: 26 December 2021

Published: 28 December 2021

Publisher's Note: MDPI stays neutral with regard to jurisdictional claims in published maps and institutional affiliations.

Copyright: (C) 2021 by the authors. Licensee MDPI, Basel, Switzerland. This article is an open access article distributed under the terms and conditions of the Creative Commons Attribution (CC BY) license (https:// creativecommons.org/licenses/by/ $4.0 /)$.

\begin{abstract}
Swine play an important role in the ecology of influenza A viruses (IAVs), acting as mixing vessels. Swine (sw) IAVs of H1N1 (including H1N1pdm09), H3N2, and H1N2 subtypes are enzootic in pigs globally, with different geographic distributions. This study investigated the genetic diversity of swIAVs detected during passive surveillance of pig farms in Northern Italy between 2017 and 2020. A total of 672 samples, IAV-positive according to RT-PCR, were subtyped by multiplex RT-PCR. A selection of strains was fully sequenced. High genotypic diversity was detected among the H1N1 and H1N2 strains, while the H3N2 strains showed a stable genetic pattern. The hemagglutinin of the H1Nx swIAVs belonged to HA-1A, HA-1B, and HA-1C lineages. Increasing variability was found in HA-1C strains with the circulation of HA-1C.2, HA-1C.2.1 and HA-1C.2.2 sublineages. Amino acid deletions in the HA-1C receptor binding site were observed and antigenic drift was confirmed. HA-1B strains were mostly represented by the $\Delta 146-147$ Italian lineage HA-1B.1.2.2, in combination with the 1990s human-derived NA gene. One antigenic variant cluster in HA-1A strains was identified in 2020. SwIAV circulation in pigs must be monitored continuously since the IAVs' evolution could generate strains with zoonotic potential.
\end{abstract}

Keywords: influenza A virus; swine; genetic characterization; antigenic characterization; subtyping

\section{Introduction}

Swine influenza viruses are a common cause of respiratory disease in pigs. Given their role as a mixing vessel for viruses of human and avian origin, swine are important for the influenza A viruses' (IAV) ecology [1]. Pigs have, in fact, both human IAV $\alpha 2,6-$ galactose ( $\alpha 2,6-G a l)$-linked and avian IAV-preferred sialic acid $\alpha 2,3-$ Gal-linked receptors [2]. Therefore, swine could be infected by multiple-origin IAV strains and play a role in the generation of potential new pandemic IAV strains, as occurred in 2009 [3].

Moreover, the eight-RNA segmented genome of IAVs contributes to the continuous evolution and reassortment of the circulating strains.

In particular, strains that endemically infect pigs in Europe are the product of mixing events among human, avian, and swine-origin strains [4,5]. The high incidence of IAVs in pigs makes the EU swine population an important reservoir for emerging new strains [6]. The introduction of viral variants into swine, with reverse zoonosis events from humans, and subsequent antigenic evolution has been demonstrated worldwide [7]. 
Recently, a new $\mathrm{H} 1$ nomenclature was proposed to better classify universally $\mathrm{H} 1$ lineages: the HA-1A classical lineage, which also includes the H1N1pdm09 lineage, related to the 1918 human influenza pandemic; HA-1B human seasonal lineage; and the HA-1C Eurasian avian lineage [8]. These three major lineages were further divided into second-, third-, and fourth-order clades.

To date, four main subtypes of swIAV circulate in Europe:

a. "Avian-like" swine H1N1 (H1avN1, clade HA-1C) lineage, which appeared in 1979 with genes of avian origin and adapted in swine;

b. "Human-like" H3N2 lineage, originating from the reassortment of human-like swine H3N2 and a H1avN1 in 1984;

c. "Human-like" H1N2 (H1huN2, clade HA-1B) lineage, originating from a human-like H3N2 and a seasonal human H1N1 reassortment in 1994;

d. "Pandemic 2009"-origin H1N1 (H1N1pdm09, clade HA-1A), circulating in the swine population since 2009.

At the farm level in Europe, H1avN1 is the dominant subtype (39.2\%), followed by other reassortant strains: H1avN2 (12.6\%), H1pdm09 subtypes composed of 4.2\% H1pdmN1pdm and 4.5\% H1pdm09Nx, H1huN2 (11.4\%). The H3N2 strains remains at low levels of detection $(3.9 \%)$ with differences in their circulation at regional level $[6,9]$.

The high incidence of IAV infection in the European swine population and the cocirculation of these different lineages contributed to the generation of reassortant strains with different combinations of swine, avian, and human (seasonal and pandemic) genes [6]. Some of these new strains emerged and replaced the endemic pig swIAV strains; in the UK, the H1N1pdm09 replaced the H1Nx strains; in Denmark, H1avN2 (H1N2dk) supplanted H1huN2 strains [10]; and a new H3huN2 reassortant strain appeared in Danish and German pig herds in 2015/2016 [11,12]. Lineages of H1N1pdm09 strains adapted to swine have been described in several countries [13-15]. Moreover, in northern European countries (Germany, Denmark, Sweden), the H1huN2 was replaced by novel reassortant H1pdm09N2 and H1avN2 strains [14], increasing the genetic and antigenic variability described among the HA-1A and HA-1C lineages, cocirculating with different NA genes [5,6,9,16-18]. The emergence of these drifted and swine-adapted strains is evidence of the active circulation of swine influenza viruses among European pig herds.

In Italy, we previously described an increasing trend in genetic variability observed in swIAVs isolated in pig farms from 2010 to 2015 with the appearance of H1N1 and H1N2 subtypes, presenting different gene combinations [19]. Moreover, the H1huN2 (i.e., A/swine/Italy/4675/2003, H1clade 1B.1.2.2) subtype, circulating in Italian farms and characterized by a double deletion in the HA1 region and an N2 of seasonal human origin introduced in 2000, has gradually replaced the former European H1huN2 (Scot/94-like) virus [4].

Recently, the presence of pre-pandemic potential features in the European swIAV population has been shown, such as ferret transmissibility and extensive antigenic diversification with low reactivity with human donors' sera [6]. These factors demonstrate the importance of monitoring circulating swIAV variants and establishing efforts at a national level. In addition, mutations able to confer resistance to $\mathrm{MxA}$, an interferon-induced host restriction factor, were found in the NP gene of both pandemic 2009 and Eurasian avian-like swine IAV lineage $[6,20]$.

In this study, we described the genetic diversification of Italian swIAVs, with particular emphasis on H1 strains, detected in respiratory outbreaks in pig farms between 2017 and 2020.

HA-1A, HA-1B, and HA-1C were detected among H1Nx swIAVs, and the highest variability was found in HA-1C strains with the circulation of imported lineages with high internal gene variability. Three different combinations of amino-acid (aa) deletions in the HA-1C were observed and antigenic drift was confirmed. On the other hand, the HA-1B lineage was still mainly represented by the previously characterized Italian HA-1B.1.2.2-N2 strain [21], showing that this lineage has become well adapted within the pig population. 
Compared to the 2010-2015 period, we observed an increased circulation of HA-1A among $\mathrm{H} 1$ strains, and a new genetic and antigenic cluster was identified in 2020. High genotypic diversity was detected among the H1N1 and H1N2 strains, whilst the H3N2 strains showed a stable genetic pattern.

\section{Materials and Methods}

A total of 9441 samples (nasal swabs or lungs) were collected between 2017 and 2020 in 1533 swine farms affected by respiratory disease and located in Northern Italian regions (Lombardia, Emilia Romagna, Veneto, Piemonte, and Friuli Venezia Giulia) characterized by a high density of pigs. In detail, the samples were delivered for diagnostic purposes to IZSLER (1454 farms, 8714 samples) or IZSVe (79 farms, 727 samples) diagnostic laboratories. Samples were tested in the two aforementioned laboratories with different workflows, as described below.

Viral RNA was extracted from $100 \mu \mathrm{L}$ of homogenized samples using a One for All vet kit (Indical Bioscience GmbH, Leipzig, Germany) according to manufacturer's instructions by IZLER. M gene real-time RT-PCR Influenza A virus screening was performed on clinical samples as previously described [22]. Six hundred and seventeen swIAV-positive samples, from independent outbreaks, collected from 397 farms, were sub-typed by IZSLER in order to have a prompt subtype identification by a nested RTPCR. For this protocol, viral RNA was first amplified with one pair of influenza-specific primers [23] (UNI12 5'GCCGGAGCTCTGCAGATATCAGCRAAAGCAGG3' and UNI13 $5^{\prime}$ GCCGGAGCTCTGCAGATATCAGTAGAAACAAGG 3') at a $10 \mathrm{pmol} / \mu \mathrm{L}$ concentration using SuperScript ${ }^{\mathrm{TM}}$ III RT/Platinum ${ }^{\mathrm{TM} T a q}$ High Fidelity (Thermo Fisher Scientific, Milan, Italy). The IAV RT-PCR included a $2.5 \mu \mathrm{L}$ RNA template, $0.5 \mu \mathrm{L}$ forward and $0.5 \mu \mathrm{L}$ reverse primer, $12.5 \mu \mathrm{L}$ reaction mix, $0.5 \mu \mathrm{L}$ SuperScript III RT/Platinum Taq mix, and $8.5 \mu \mathrm{L}$ RNase free water to obtain a total volume of $25 \mu \mathrm{L}$. In this protocol, all influenza segments were amplified simultaneously using one-step RT-PCR and one set of primers adapted to the conserved $3^{\prime}$ and $5^{\prime}$ segment ends. The cycling conditions were as follows: a reversetranscription step of $30 \mathrm{~min}$ at $42{ }^{\circ} \mathrm{C}$, and then denaturation at $94{ }^{\circ} \mathrm{C}$ for $2 \mathrm{~min}$, followed by five cycles of $94{ }^{\circ} \mathrm{C}$ for $30 \mathrm{~s}, 45^{\circ} \mathrm{C}$ for $30 \mathrm{~s}$ and $68^{\circ} \mathrm{C}$ for $3 \mathrm{~min}$, followed by additional 30 cycles of $94^{\circ} \mathrm{C}$ for $30 \mathrm{~s}, 57^{\circ} \mathrm{C}$ for $30 \mathrm{~s}$ and $68^{\circ} \mathrm{C}$ for $3 \mathrm{~min}$ with a final elongation step at $68^{\circ} \mathrm{C}$ for $5 \mathrm{~min}$. The HA and NA subtype was detected using a double-nested PCR using the product of the first universal RT-PCR as a template. Two separated multiplex reactions were set up to amplify HA and NA genes with the HotStarTaq Master Mix Kit (Qiagen, Milan, Italy) using primers listed in Table 1. Each multiplex PCR was performed in a reaction mixture of $25 \mu \mathrm{L}$ containing $12.5 \mu \mathrm{L}$ of HotStarTaq Master Mix $2 \times, 5 \mu \mathrm{L}$ of $\mathrm{H}_{2} \mathrm{O}, 12.5$ pmol of each primer H1N2_for, H1N2_rev, H1N1_for, H1N1_rev, N1_for, N1_rev, N2_for, N2_rev, 25pmol of primers SW-H1 FOR 107, SW H1 REV 623, H3_for, H3_rev, and $2.5 \mu \mathrm{L}$ of DNA product of the universal RT-PCR pre-diluted 1:20. Amplifications were obtained with the following cycling conditions: $15 \mathrm{~min}$ at $95^{\circ} \mathrm{C}$ of initial denaturation, then 40 cycles at $94{ }^{\circ} \mathrm{C}$ for $45 \mathrm{~s}$, annealing at $55{ }^{\circ} \mathrm{C}$ for $45 \mathrm{~s}$, and extension at $72{ }^{\circ} \mathrm{C}$ for $1 \mathrm{~min}$ followed by an extension step at $72{ }^{\circ} \mathrm{C}$ for $7 \mathrm{~min}$. PCR amplicons were separated and visualized on $2 \%$ agarose gel. Viral subtypes were differentiated according to the length of each amplification product (Table 1) and classified preliminarily as H1N1, H1N2, H3N2, and H1N1pdm09. 
Table 1. List of primers used in the nested multiplex PCR for virus subtyping and PCR product expected size.

\begin{tabular}{|c|c|c|c|}
\hline Primer Name & Sequence $5^{\prime}-3^{\prime}$ & Subtype-Ref & $\begin{array}{l}\text { PCR Product } \\
\text { Expected Size }\end{array}$ \\
\hline $\begin{array}{l}\text { H1N2_for (H1-1B) } \\
\text { H1N2_rev (H1-1B) }\end{array}$ & $\begin{array}{l}\text { GCTACCATGCGAACAATTCA } \\
\text { TCAGCATTTGGTGTTTCTGC }\end{array}$ & H1 [19] & 241 \\
\hline $\begin{array}{l}\text { H1N1_for (H1-1C) } \\
\text { H1N1_rev (H1-1C) }\end{array}$ & $\begin{array}{l}\text { CTGCACTGAAAGCTGACACC } \\
\text { GCTGCTCССTTAATTCCTCA }\end{array}$ & H1 [19] & 327 \\
\hline $\begin{array}{l}\text { SW-H1 FOR } 107 \text { (H1-1A) } \\
\text { SW H1 REV } 623 \text { (H1-1A) }\end{array}$ & $\begin{array}{l}\text { CAGACACTGTAGACACAGTAC } \\
\text { CTAGTAGATGGATGGTGAATGC }\end{array}$ & H1pdm09 [20] & 516 \\
\hline $\begin{array}{l}\text { H3_for } \\
\text { H3_rev }\end{array}$ & $\begin{array}{l}\text { CARATTGARGTGACHAATGC } \\
\text { GGTGCATCTGAYCTCATTA }\end{array}$ & H3 [19] & 722 \\
\hline $\begin{array}{l}\text { N1_for } \\
\text { N1_rev }\end{array}$ & $\begin{array}{c}\text { TGAAATACAATGGCATAATAAC } \\
\text { GGATCCCAAATCATCTCAAA }\end{array}$ & N1 [19] & 514 \\
\hline $\begin{array}{l}\text { N2_for } \\
\text { N2_rev }\end{array}$ & $\begin{array}{l}\text { GGAAAAGCATGGCTGCAT } \\
\text { GTGCCACAAAACACAACAAT }\end{array}$ & N2 [19] & 791 \\
\hline
\end{tabular}

Viral RNA was extracted from $100 \mu \mathrm{L}$ of homogenized samples using a KingFisher ${ }^{\mathrm{TM}}$ Flex Purification System (Waltham, MA, USA), a semiautomated method (Thermo Fisher Scientific) with the ID GENE MAG UNIVERSAL EXTRACTION KIT (ID Vet Grabels, France) by IZSVe laboratory. The RT-PCR targeting the M gene, described by Hoffmann et al., 2010 [24], was used for the screening of the samples. Fifty-five positive samples collected during different outbreaks from 55 farms were subtyped by IZSVe by an hemagglutinin- and neuraminidase-specific tetra- and triplex real-time RT-PCR [25].

Both laboratories attempted virus isolation of positive samples, inoculating 11-day-old SPF embryonated chicken eggs or cell cultures (MDCK or CACO-2) [26,27]. A selection of 413 isolated swIAVs or positive diagnostic samples were further analyzed from a genetic and antigenic point of view. Selected swine viruses came from independent respiratory outbreaks; when more than one virus was isolated from the same respiratory outbreak, we selected only one of them for further analysis.

Viral RNA was extracted from isolated viruses or clinical samples as described above and full genome sequencing was performed as previously described by Lycett et al. [28] using SuperScript ${ }^{\circledR}$ III One-Step RT-PCR System with Platinum ${ }^{\circledR}$ Taq High Fidelity (Thermo Fisher Scientific). RT-PCR products were purified with NucleoSpin ${ }^{\circledR}$ Gel and PCR Clean-up (Macherey-Nagel, Carlo Erba, Italy). DNA libraries were made with an NEXTERA-XT kit (Illumina Inc. San Diego, CA, USA) according to the manufacturer's instructions. Pooled libraries were sequenced on a MiSeq Instrument (Illumina) by using a Miseq Reagent nano Kit v2 in a 150-cycle paired-end run. Data were de novo assembled by the CLC genomic workbench v.11 (Qiagen, Milan, Italy). Sequences of all the strains of the study were submitted to Genbank (accession numbers MW220195 -MW220833_2017, MW170386-MW171247, MW169476- MW170361, MW244100-MW244371, MW621504-MW621857, MZ404272-MZ404287, MZ483984-MZ484071, MZ477531-MZ477743, MZ541572-MZ541601, MZ542323).

All eight gene segments were preliminarily analyzed, performing a nucleotide query step in the Genbank database (http:/ / blast.ncbi.nlm.nih.gov / BLAST; accessed on 21 October 2021) and identifying closely related sequences. European swine IAV reference sequences were retrieved from the Genbank Influenza virus resource database (https: //www.ncbi.nlm.nih.gov/genomes/FLU/Database/nph-select.cgi?go=database; accessed on 21 October 2021). Gene sequences were then aligned with ClustalW using MEGAX [29]. For the purposes of lineage assignment, phylogenetic trees of the individual segments were inferred with the maximum likelihood (ML) method implemented in IQ-TREE-2 [30-32]. 
The robustness of the ML trees was statically evaluated by bootstrap analysis with 5000 bootstrap samples. A likelihood mapping analysis was conducted in IQ-TREE2 with 25,000 quartets for each alignment, with the model being automatically selected.

Trees were visualized using Figtree v. 1.4.4 (http:/ / tree.bio.ed.ac.uk/software/figtree accessed on 20 December 2021) or using CLC genomic workbench v.11. The origin of each segment was named by its clustering with reference strains. In addition, swine H1 sequences were analyzed and named using the swine H1 influenza classification tool (http: / / www.fludb.org; accessed on 21 October 2021) [8].

Due to the segmented genome, each virus had to be described with a specific gene combination, and viruses were further classified into numbered genotypes.

The sequences of the swIAV HA, NA, and NP gene segments were aligned using ClustalW as described above. The predicted amino acid (aa) sequence was obtained for each gene. In addition, in order to analyze the mutations able to confer resistance to $\mathrm{MxA}$, amino acid positions 53, 100, and 313 were analyzed for NP of the H1N1pdm09 lineage [33,34] and positions 48,98 , and 99 for NP of avian origin $[6,20]$.

Selected H1 strains belonging to recently identified genetic clusters were tested in triplicate by $\mathrm{HI}$ test using hyperimmune pig sera against the following Italian strains: A/swine/Italy/284922/2009 H1N2 (1B.1.2.2), A/swine/Italy/311368/2013 H1N1 (1C.2.1), A/swine/Italy/311349/2013 H3N2, A/swine/Italy/282866/2013 H1N1 (1A.3.3.2) [27]. These hyperimmune sera exhibited HI titers against the homologous viruses that ranged between 1:640 and 1:2560.

\section{Results}

\section{1. swIAV Subtypes Circulation over the Four Years (2017-2020)}

A total of 1533 pig farms (9441 samples) presenting respiratory problems, located in an area with a high density of pig farms, were examined for the presence of swIAVs by real-time RT-PCR over a four-year period (2017-2020); 676 of them (44\%) tested positive at least once with $\mathrm{M}$ gene RT-PCR.

During the examined period, 672 swIAVs were subtyped from temporally different outbreaks occurred in different times.

The H1N2 subtype was detected in $45 \%$ of the outbreaks, followed by the H1N1 subtype (35\%), H3N2 subtype (12\%), and H1N1pdm09 (6\%), with the sporadic detection of mixed infections with two subtypes (2\%). The detection of H1N1 and H1N2 was stable in the study period, while H3N2 detection decreased from 12 to $15 \%$ in $2017-2019$ to 5\% in 2020. On the other hand, the positivity for H1N1pdm09 increased rapidly from 1\% in 2017 to $15 \%$ in 2020 (Table 2).

Table 2. swIAV subtype positivity per year considered. Strains were classified in subtypes: H1N1 (H1-1B/H1-1C-N1), H1N1pdm09 (H1-1A-N1), H1N2 (H1-1A/H1-1B/H1-1C-N2).

\begin{tabular}{cccccccc}
\hline & $\begin{array}{c}n \text {. of } \\
\text { Subtyped } \\
\text { Outbreaks }\end{array}$ & H1N1 & H1N2 & H3N2 & H3N1 & $\begin{array}{c}\text { H1N1 } \\
\text { pdm09 }\end{array}$ & $\begin{array}{c}\text { Mixed } \\
\text { Infection }\end{array}$ \\
\hline 2017 & 196 & $41 \%$ & $41 \%$ & $15 \%$ & $0 \%$ & $1 \%$ & $2 \%$ \\
\hline 2018 & 164 & $36 \%$ & $48 \%$ & $12 \%$ & $1 \%$ & $3 \%$ & $1 \%$ \\
\hline 2019 & 149 & $31 \%$ & $44 \%$ & $17 \%$ & $1 \%$ & $5 \%$ & $2 \%$ \\
\hline 2020 & 163 & $31 \%$ & $47 \%$ & $5 \%$ & $0 \%$ & $15 \%$ & $3 \%$ \\
\hline $2017-2020$ & 672 & $35 \%$ & $45 \%$ & $12 \%$ & $0 \%$ & $6 \%$ & $2 \%$ \\
\hline
\end{tabular}

\subsection{Genotypes Analysis}

Using full genome sequencing, we analyzed $358 \mathrm{H} 1 \mathrm{Nx}(171 \mathrm{H} 1 \mathrm{~N} 2,160 \mathrm{H} 1 \mathrm{~N} 1$, and 27 H1N1pdm09) and 55 H3N2 swIAV strains (Tables 3 and 4). A preliminary phylogenetic analysis of the whole genomes of Italian isolates, with the arrangement of the eight genes, allowed us to further assign each virus to a specific lineage, genotype, and origin. 
H1N2 was the subtype with the highest genotypic variability (with the detection of 18 different gene combinations), followed by H1N1 (HA-1C lineage) with seven genotypes and H1N1pdm09 (HA-1A lineage) with three genotypes. The relative proportion of these genotypes showed the dominance of the endemic strains for H1N2 (HA-1B.1.2.2-ItN2, genotype F) and H1N1 (HA-1C-N1av, genotype A). It is noteworthy that the H1N1pdm09 underwent multiple reassortment events with the identification, in 2020, of two previously undescribed H1N1pdm09-derived genotypes (HA-1A.3.3.2-N1av, genotypes 31 and 32) (Figure 1, Table 4).

Table 3. List of genotypes detected among 171 analyzed H1N2 strains and 55 H3N2 and relative percentages. Genotype nomenclatures assigned as described previously [5,6]. Undescribed genotypes $\left.{ }^{*}\right)$ are numbered arbitrarily [19]. H1-clade are classified according to [8], and H3(84) correspond to Ghent-like. NA lineages assigned as described in [5,6] (N2g Ghent-like; N2s, Scotland-like; It-N2; A/swine/Italy/4675/2003).

\begin{tabular}{|c|c|c|c|c|c|c|c|c|c|c|}
\hline Subtype & Nomenclature & HA & NA & PB2 & PB1 & PA & NP & $\mathbf{M}$ & NS & $\%$ \\
\hline \multirow{18}{*}{ H1N2 } & $\mathrm{F}$ & 1B.1.2.2 & It-N2 & av & av & av & av & av & av & $38.6 \%$ \\
\hline & $\mathrm{AH}$ & 1C.2 & N2g & pdm & pdm & pdm & pdm & pdm & av & $12.9 \%$ \\
\hline & \multirow{2}{*}{$\mathrm{T}$} & 1C.2.1 & N2g & pdm & pdm & pdm & $\mathrm{pdm}$ & $\mathrm{pdm}$ & pdm & $0.6 \%$ \\
\hline & & $1 C .2$ & $\mathrm{~N} 2 \mathrm{~g}$ & pdm & pdm & pdm & pdm & pdm & pdm & $17.5 \%$ \\
\hline & \multirow{2}{*}{$\mathrm{L}$} & 1C.2.1 & It-N2 & av & av & av & av & av & av & $1.8 \%$ \\
\hline & & $1 C .2$ & It-N2 & av & av & av & av & av & av & $2.3 \%$ \\
\hline & \multirow{2}{*}{$\mathrm{D}$} & 1C.2.1 & N2g & av & av & av & av & av & av & $5.8 \%$ \\
\hline & & 1C.2 & N2g & av & av & av & av & av & av & $7.0 \%$ \\
\hline & \multirow[b]{2}{*}{$\mathrm{E}$} & 1B.1.2.1 & N2g & av & av & av & av & av & av & $1.2 \%$ \\
\hline & & 1B.1.2.2 & $\mathrm{N} 2 \mathrm{~g}$ & av & av & av & av & av & av & $2.3 \%$ \\
\hline & $7 *$ & 1B.1.2.2 & It-N2 & pdm & pdm & pdm & pdm & pdm & pdm & $3.5 \%$ \\
\hline & $26 *$ & 1C.2 & N2g & pdm & $\mathrm{pdm}$ & $\mathrm{pdm}$ & $\mathrm{pdm}$ & pdm & av & $0.6 \%$ \\
\hline & $27^{*}$ & 1B.1.2.2 & It-N2 & av & av & av & av & pdm & av & $1.8 \%$ \\
\hline & $29 *$ & 1B.1.2.2 & It-N2 & av & av & av & pdm & pdm & av & $0.6 \%$ \\
\hline & $30 *$ & 1A.3.3.2 & It-N2 & av & av & av & av & av & av & $0.6 \%$ \\
\hline & \multirow{2}{*}{ G } & 1C.2.2 & N2s & av & av & av & av & av & av & $1.2 \%$ \\
\hline & & 1C.2 & $\mathrm{N} 2 \mathrm{~s}$ & av & av & av & av & av & av & $1.2 \%$ \\
\hline & $\mathrm{R}$ & 1A.3.3.2 & N2g & pdm & pdm & pdm & pdm & pdm & pdm & $0.6 \%$ \\
\hline H3N2 & & Н3(84) & N2g & av & av & av & av & av & av & $100 \%$ \\
\hline
\end{tabular}

Table 4. List of H1N1 detected among 187 analyzed strains and relative percentages among the subtype (H1avN1, 159 samples, H1pdm09N1, 27 samples and H1huN1, 1 sample). The genotype nomenclatures are assigned as described previously [5,6]. Undescribed genotypes $\left(^{*}\right)$ are numbered arbitrarily [19]. H1 clades are classified according to [8]. NA lineages are assigned as described in [5]; N1av: Eurasian avian-like; pdm: N1pdm09.

\begin{tabular}{|c|c|c|c|c|c|c|c|c|c|c|}
\hline Subtype & Nomenclature & HA & NA & PB2 & PB1 & PA & NP & $\mathbf{M}$ & NS & $\%$ \\
\hline \multirow{10}{*}{ H1N1 } & \multirow{3}{*}{ A } & 1C.2.1 & av & av & av & av & av & av & av & $58.3 \%$ \\
\hline & & $1 C .2$ & av & av & av & av & av & av & av & $19.3 \%$ \\
\hline & & 1C.2.2 & av & av & av & av & av & av & av & $4.3 \%$ \\
\hline & \multirow{2}{*}{$\mathrm{M}$} & 1C.2.1 & av & av & av & av & av & pdm & av & $0.5 \%$ \\
\hline & & $1 C .2$ & av & av & av & av & av & pdm & av & $1.6 \%$ \\
\hline & $\mathrm{U}$ & 1C.2.1 & av & pdm & pdm & pdm & $\mathrm{pdm}$ & pdm & pdm & $1.1 \%$ \\
\hline & $\mathrm{P}$ & 1A.3.3.2 & pdm & pdm & pdm & pdm & pdm & pdm & pdm & $8.6 \%$ \\
\hline & $31 *$ & 1A.3.3.2 & av & pdm & pdm & pdm & pdm & pdm & av & $4.3 \%$ \\
\hline & $32 *$ & 1A.3.3.2 & av & pdm & pdm & pdm & pdm & pdm & pdm & $1.6 \%$ \\
\hline & $\mathrm{H}$ & 1B.1.2.2 & av & av & av & av & av & av & av & $0.5 \%$ \\
\hline
\end{tabular}




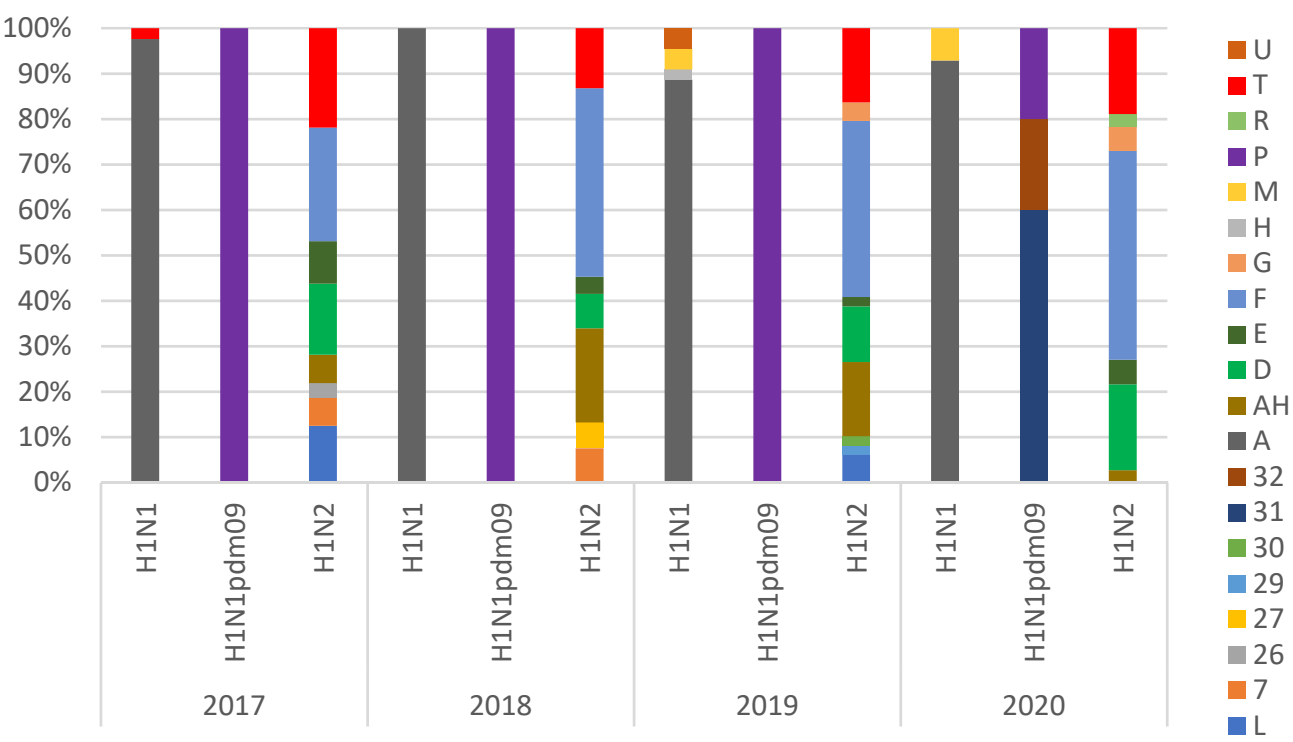

Figure 1. Percentage of genotypic diversity of H1 swIAV Italian strains per year detected between 2017 and 2020. Genotype identification is described in Tables 3 and 4. Strains were classified in subtypes: H1N1 (HA-1B/HA-1C-N1), H1N1pdm09 (HA-1A-N1), H1N2 (HA-1A/HA-1B/HA-1C-N2).

HA-1B.1.2.2 was almost the only human-like HA detected in Italy in H1N2 strains together with reassortant strains with HA-1C-N2, which represent, respectively, $38.6 \%$ and $50.9 \%$ of the identified H1N2 lineages (Figure 2). The H1N1 genotypic diversity increased since 2019, with the detection of several introductions of different genotypes harboring HA-1C.2 in the country (Figures 1 and 2, Table 4).

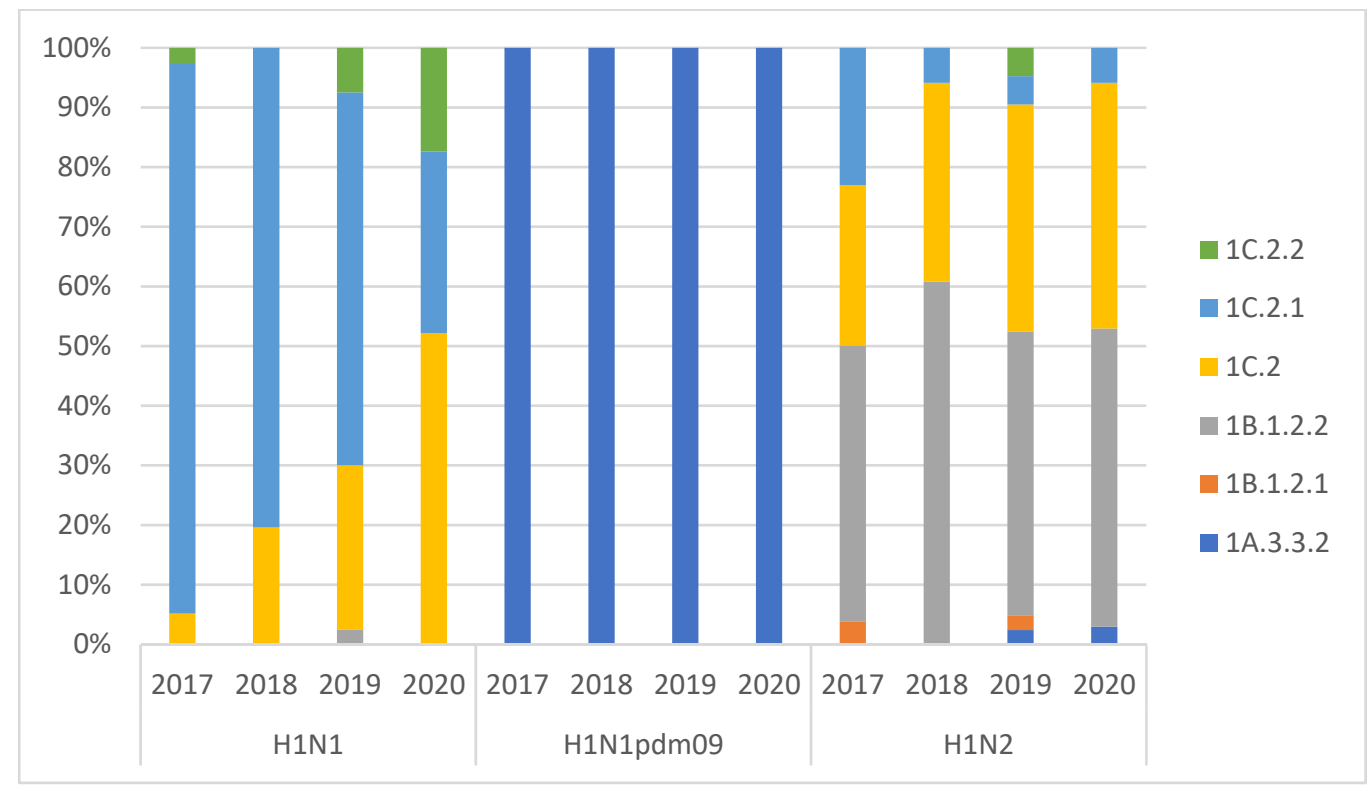

Figure 2. H1 lineage differentiation per year of collection of swIAVs detected. H1 nomenclature was applied as described by Anderson et al. Strains were classified in subtypes: H1N1 (HA-1B/HA-1CN1), H1N1pdm09 (HA-1A-N1), H1N2 (HA-1A/HA-1B/HA-1C-N2).

All of the 55 sequenced H3N2 strains had the same genotype, with HA and NA genes Ghent-84 derived and internal genes of avian origin (Table 3). 


\subsection{Phylogenetic Analysis of Italian swIAVs}

HA-1A strains circulating up to 2019 (clade 1A.3.3.2) confirmed the data collected previously [19] with the cocirculation of a group of swine-adapted strains, swine-D Italy1 (sub-cluster b, Figure 3) detected in Italy since 2013 and strains related to seasonal H1pdm09 strains (sub-cluster c, Figure 3). In 2020, we detected, in 11 farms, the circulation of a new variant of H1N1pdm09, swine-D Italy2 (sub-cluster a, Figure 3), whose closest related strains were H1N2 strains detected in Denmark and Germany in the years 2014-2015 (i.e., A/swine/Denmark/10781/2014, A/swine/Wolfaghen/21852/2015). The variant presented two different reassortant patterns: genotype31, characterized by N1 and NS of Eurasian avian-like origin and the remaining internal genes of pdm09 origin, and genotype32, with only N1 Eurasian avian-like origin and all the remaining genes of pdm09 origin (Table 4). All of these 11 strains shared a common N1 gene, clustering apart from the cocirculating avian-like N1 (A/swine/Bakum/3543/1998 H1N1) gene associated to Italian HA-1C strains (Figure 4) and slightly related to strains detected in Denmark and Germany (i.e., A/swine/Denmark/P5U4NA/2016 H1N1). The recent strains, belonging to subcluster $b$ and $c$, reacted in HI tests (Table 5) with the reference pandemic swine antiserum against strain A/swine/Italy/282866/2013 (sub-cluster b, Figure 3). On the other hand, the new strains of sub-cluster a were antigenically different from HA-1A swIAV strains circulating previously in Italy and did not react with any IZSLER laboratory reference antiserum tested using HI testing (Table 5). Strains related to the A/swine/Italy/290271/2009 (Genotype P, Human-like1 cluster) have not been detected since 2013 in Italian pigs. Two farms tested positive for the HA-1A, introduced from 2012 human seasonal H1N1pdm09 strains, detected since 2014 (i.e., A/swine/Italy/312118/2014, genotype P, Human-like2 cluster). Only two strains showed a relation to the HA-1A antigenic variant circulating in Germany Wachtum/2014-like [16], including the Sw-L strains detected in Denmark recently [18].

The phylogenetic analysis of $\mathrm{H} 1$ of human origin HA-1B genes (Figure 5) showed the persistence, in Italy, of the 1B.1.2.2 clade, $\Delta 146-147$ variant, previously described [21]. Strains collected after 2017 distributed into two sub-clusters, still circulating, associated with it-N2 among pig farms (Supplementary Figure S1). Sporadic detections of human origin 1B.1.2.1 were identified.

The genetic analysis of the circulating H1avN1 viruses showed an increased variability with respect to the situation described in 2015 [19], since multiple variants of H1C were detected. Different sub-clusters, grouped in the 1C.2 lineage with German and Danish strains, in combination with both N2 and N1 genes, have been identified since 2019 (Figure 6). Moreover, in this lineage, five different patterns of deletion in the receptor binding site region [35] were identified according to H1 numbering [36]: $\Delta 127(n=13)$, $\Delta 130(n=2), \Delta 120,130(n=17), \Delta 128,155(n=15)$, and $\Delta 155(n=1)$.

Deletions $\Delta 130$ and $\Delta 120,130$ were present in two strains, clustering with Italian sequences, isolated in Denmark in 2006 (A/swine/Denmark/10547-4/2006 H1N1) and 2016 (A/swine/Denmark/AR8888/2016), respectively (Supplementary Figure S3), and the deletion $\Delta 127$ was present in Danish strains detected in 2017 . Representative strains for each of the $\Delta 120,130 ; \Delta 128,155 ; \Delta 127$ were tested by HI test using Italian reference antiserum A/swine/Italy/311368/2013, lineage 1C.2.1, with no reaction (Table 5). The complete, non-collapsed, phylogenetic H1 tree is available in Supplementary Figure S3. 


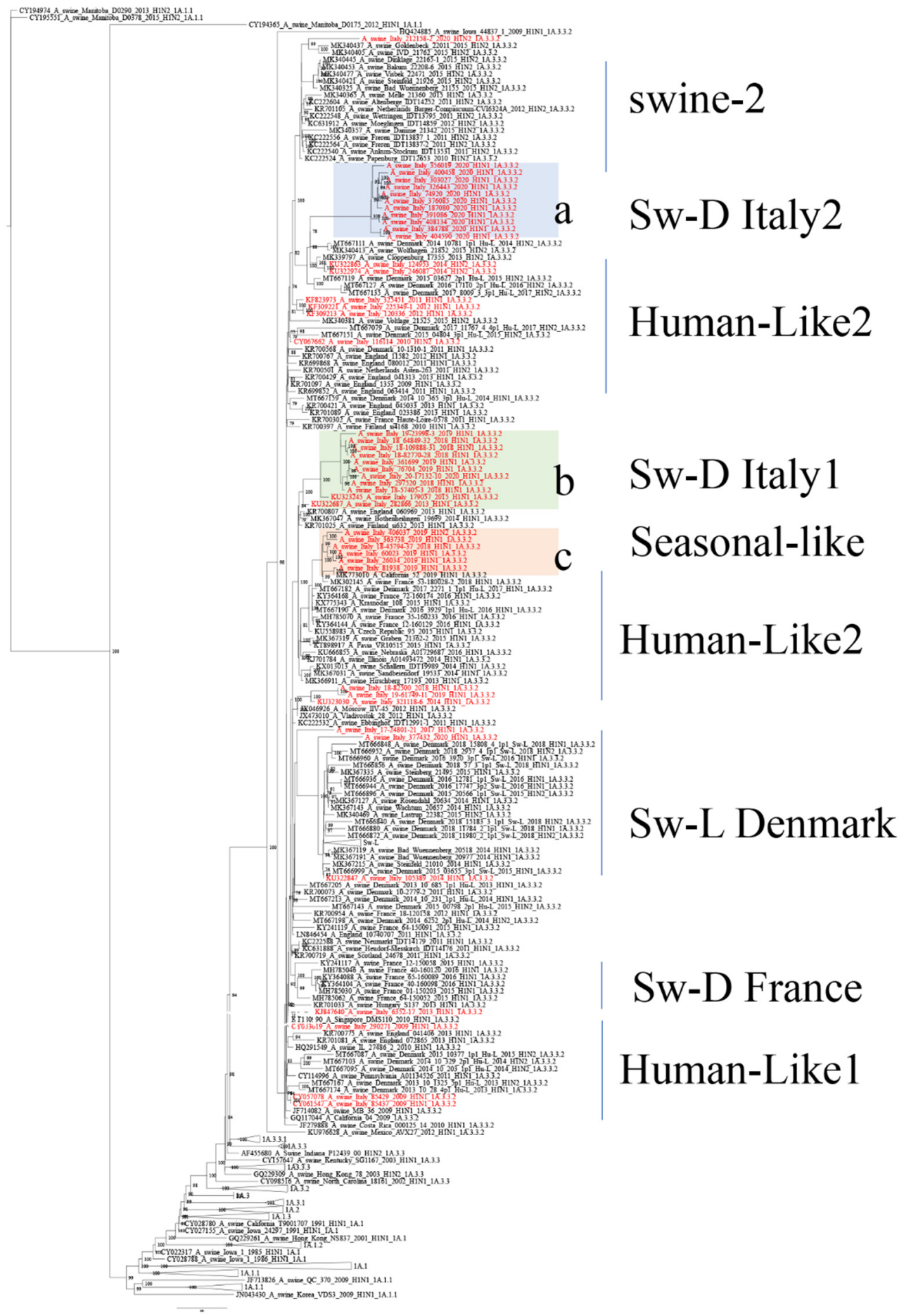

Figure 3. ML phylogenetic tree of 270 HA-H1A with the 29 HA-1A, 1A.3.3.2, sequences (1611 nucleotides) of strains analyzed in this work. Tree is inferred with European reference sequences retrieved from Genbank collected in the years 2009-2020 with the reference sequences used to construct the global swine $\mathrm{H} 1$ clade classification reference tree, which is used to classify the clade of the HA/H1 viruses [8]. The three main sub-clusters circulating recently in the country (a-c) are highlighted in light blue, green, and pink, respectively and the closest HA sequences matching strains in sub-clusters a, b and c are included. Italian sequences are in red;. Bootstrap values under $70 \%$ are not shown; scale bar represents number of nucleotide substitutions per nucleotide site. Sequences retrieved from Genbank are identified by their accession number. Clusters are named according to recent papers describing swIAVs in Europe $[6,9,18]$. 


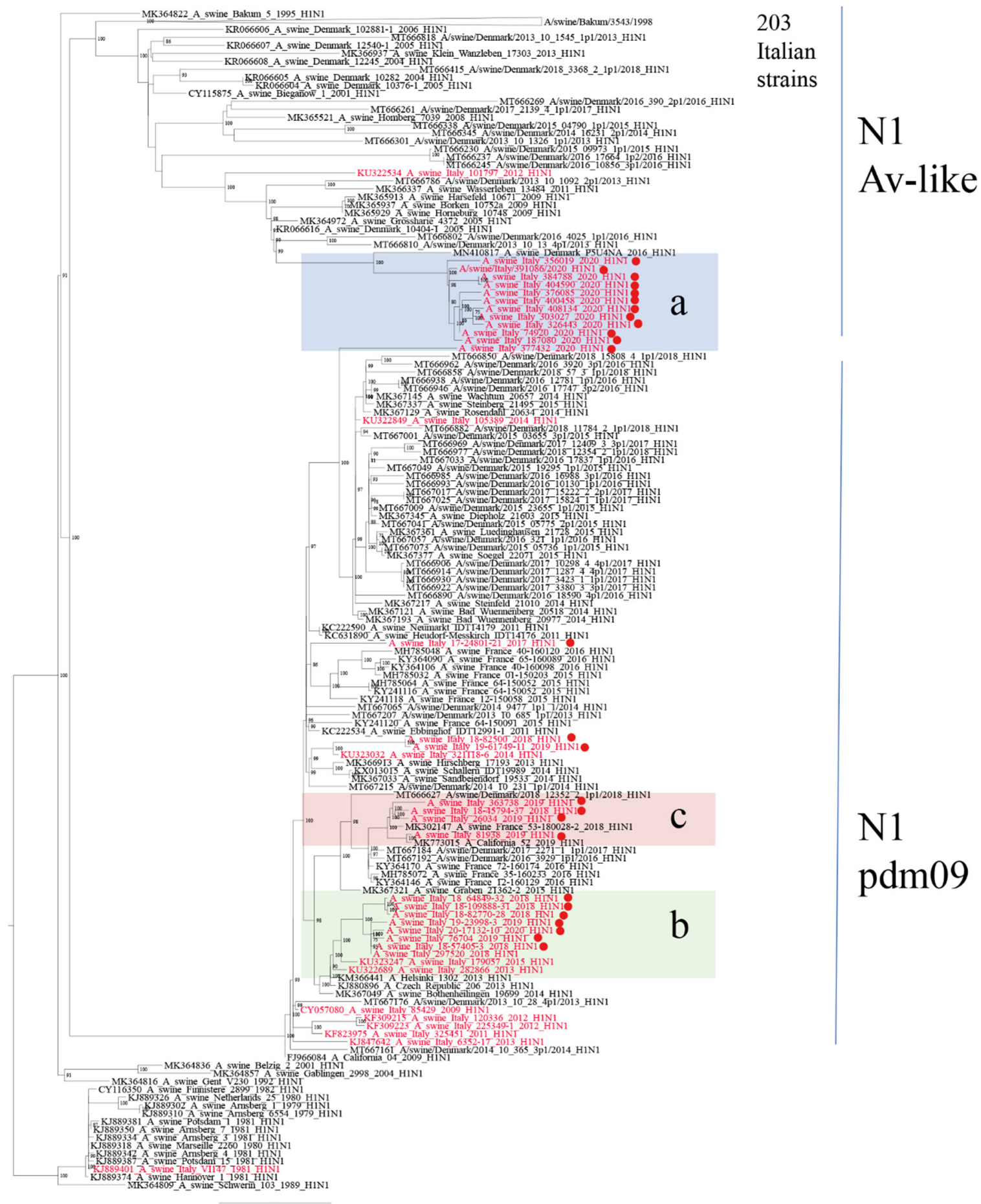

Figure 4. Phylogenetic tree of 199 N1 sequences (1373 nucleotides) of strains sequenced in this work analyzed with 442 representative swine and human N1 sequences, collected from 2009, retrieved from Genbank; the closest NA sequences matching strains in sub-clusters a, b and c are included. Italian sequences are in red with dots highlighting recent strains (2017-2020). The three main sub-cluster $(\mathbf{a}-\mathbf{c})$ are highlighted in light blue, green, and pink, respectively. To simplify visualization, a group of 203 Italian N1 strains related to the Eurasian avian-like N1 gene A_swine_Bakum_3543_1998 have been collapsed into one branch. Bootstrap values under $70 \%$ are not shown; scale bar represents number of nucleotide substitutions per nucleotide site. Sequences retrieved from Genbank are identified by their accession number. 
Table 5. HI titers of selected strains using Italian pig hyperimmune sera produced against representative Italian 1B.1.2.2, 1C2.1, H3, and 1A.3.3.2 swIAV strains. These hyperimmune sera exhibit HI titers against homologous viruses that ranged between 1:640 and 1:5120.

\begin{tabular}{|c|c|c|c|c|c|}
\hline \multicolumn{6}{|c|}{ HI TEST RESULTS } \\
\hline VIRUS SERUM & & $\begin{array}{c}\text { A/Swine/Italy/ } \\
\text { 284922/2009 } \\
\text { H1N2 }\end{array}$ & $\begin{array}{c}\text { A/Swine/Italy/ } \\
\text { 311368/2013 } \\
\text { H1N1 }\end{array}$ & $\begin{array}{c}\text { A/Swine/Italy/ } \\
\text { 311349/2013 } \\
\text { H3N2 }\end{array}$ & $\begin{array}{c}\text { A/Swine/Italy/ } \\
\text { 282866/2013 } \\
\text { H1N1 }\end{array}$ \\
\hline & LINEAGE & 1B.1.2.2 & 1C.2.1 & H3 & 1A.3.3.2 \\
\hline $\begin{array}{c}\text { A/swine/Italy/284922/2009 } \\
\text { H1N2 }\end{array}$ & 1B.1.2.2 & 640 & $<20$ & $<20$ & $<20$ \\
\hline $\begin{array}{c}\text { A/swine/Italy/311368/2013 } \\
\text { H1N1 }\end{array}$ & 1C.2.1 & $<20$ & 1280 & $<20$ & $<20$ \\
\hline $\begin{array}{c}\text { A/swine/Italy/311349/2013 } \\
\text { H3N2 }\end{array}$ & H3 & $<20$ & $<20$ & 640 & $<20$ \\
\hline $\begin{array}{c}\text { A/swine/Italy/282866/2013 } \\
\text { H1N1 sub-cluster (b) }\end{array}$ & 1A.3.3.2 & $<20$ & $<20$ & $<20$ & 5120 \\
\hline $\begin{array}{c}\text { A/swine/Italy/326417/2020 } \\
\text { H1N1 }\end{array}$ & $\begin{array}{c}1 C .2 \\
\text { del } 128,155\end{array}$ & $<20$ & $<20$ & $<20$ & $<20$ \\
\hline $\begin{array}{c}\text { A/swine/Italy/340406/2020 } \\
\text { H1N2 }\end{array}$ & $\begin{array}{c}1 C .2 \\
\text { del } 127\end{array}$ & $<20$ & 20 & $<20$ & $<20$ \\
\hline $\begin{array}{c}\text { A/swine/Italy/381442/2020 } \\
\text { H1N2 }\end{array}$ & $\begin{array}{c}1 C .2 \\
\text { del } 128,155\end{array}$ & $<20$ & $<20$ & $<20$ & $<20$ \\
\hline $\begin{array}{c}\text { A/swine/Italy/37307/2020 } \\
\text { H1N2 }\end{array}$ & $\begin{array}{c}1 C .2 \\
\text { del } 120,130\end{array}$ & $<20$ & 20 & $<20$ & $<20$ \\
\hline $\begin{array}{c}\text { A/swine/Italy/31684/2020 } \\
\text { H1N2 }\end{array}$ & 1C.2.1 & $<20$ & 2560 & $<20$ & $<20$ \\
\hline $\begin{array}{c}\text { A/swine/Italy/30190/2020 } \\
\text { H1N2 }\end{array}$ & 1C.2 & $<20$ & 320 & $<20$ & 160 \\
\hline $\begin{array}{c}\text { A/swine/Italy/187080/2020 } \\
\text { H1N1 sub-cluster (a) }\end{array}$ & 1A.3.3.2 & $<20$ & $<20$ & $<20$ & $<20$ \\
\hline $\begin{array}{c}\text { A/swine/Italy/297520/2018 } \\
\text { H1N1 sub-cluster (b) }\end{array}$ & 1A.3.3.2 & $<20$ & 20 & $<20$ & 640 \\
\hline $\begin{array}{l}\text { A/swine/Italy/60023/2019 } \\
\text { H1N1 sub-cluster (c) }\end{array}$ & 1A.3.3.2 & $<20$ & 320 & $<20$ & 5120 \\
\hline
\end{tabular}




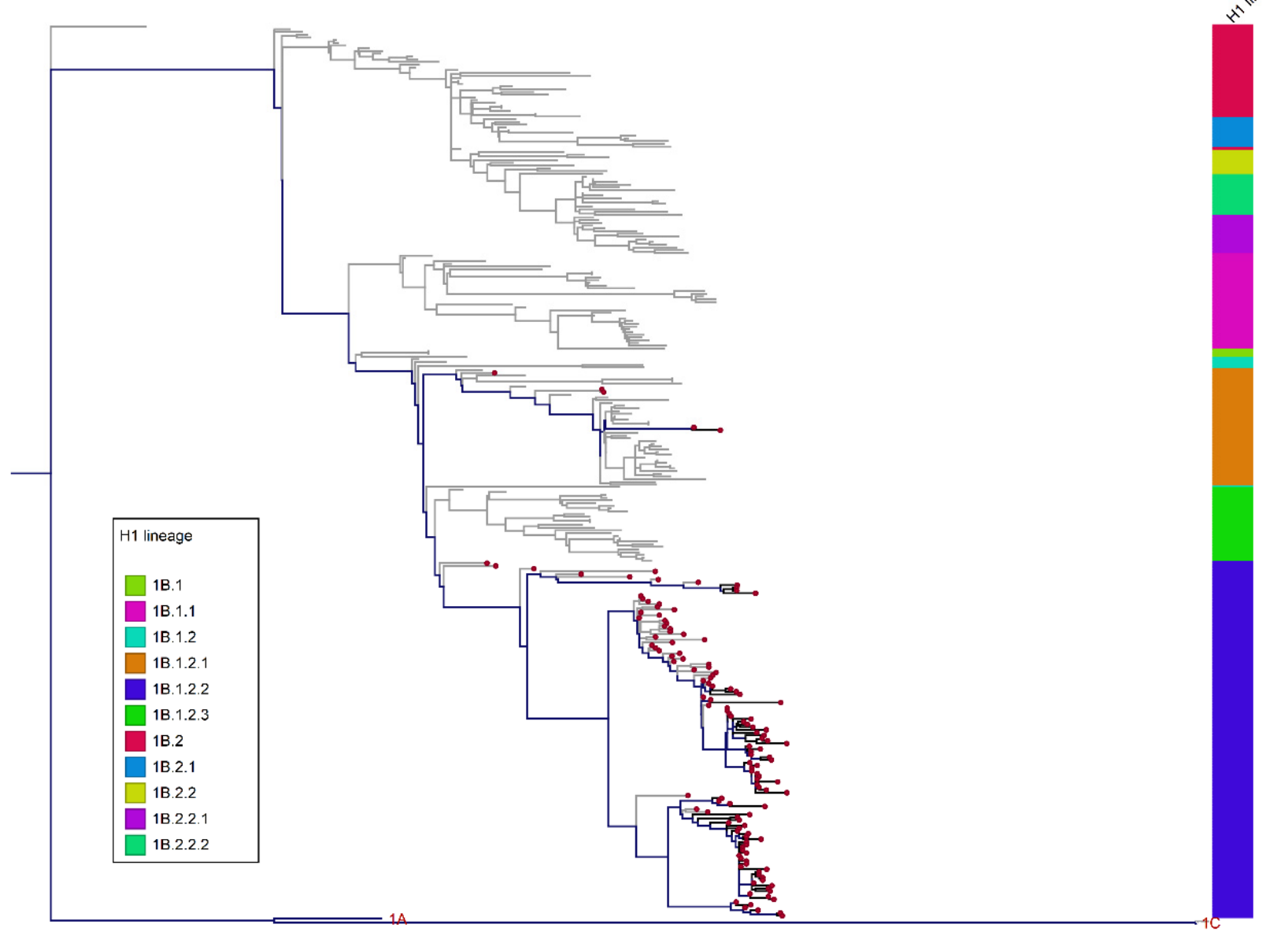

0.180

Figure 5. ML phylogenetic tree of $1460 \mathrm{HA}-\mathrm{H} 1$ sequences $(n=270 \mathrm{HA}-1 \mathrm{~A}, n=322 \mathrm{HA}-1 \mathrm{~B}$, and $n=857 \mathrm{HA}-1 \mathrm{C}$ ) with the $86 \mathrm{HA}-1 \mathrm{~B}$ sequences (1611 nucleotides) of strains analyzed in this work inferred with swine references sequences retrieved from Genbank. Scale bar represents number of nucleotide substitutions per nucleotide site. Tree visualized using CLC genomic workbench v.11. To simplify visualization, HA-1A and HA-1C branches have been collapsed. The Italian sequences are represented by red dots; the bar colors distinguish HA-1B clusters. Branch colors distinguish strains collected before 2017 (grey) or after 2017 (black).

H3N2 strains showed no significative reassortant patterns, all HA genes belonged to the H3(84) lineage and no H3huN2 variant was detected in the examined period (data not shown).

The NP gene was analyzed globally in the period considered after the alignment of 375 sequences (1441 nucleotides). Translated sequences were aligned; NP aa positions 48, 53, 98, 99, 100, and 313 were compared. MxA resistance mutations 48Q, 98K, and 99K (for avian-origin NP) and 53D, 100I, 313V (for pandemic-origin NP) were recorded. Among avian-origin NP genes (n. 298), 98\% harbored the complete set of mutations, 48Q, $98 \mathrm{~K}$, and $99 \mathrm{~K}$, able to confer resistance to mammal host MxA, and 1.3\% harbored at least one mutation $(48 \mathrm{Q})$. The analysis of NP genes $(n=77)$ of pandemic origin showed the presence of both $100 \mathrm{I}$ and $313 \mathrm{~V}$ mutations in $87 \%$ of strains, whilst only $0.9 \%$ of the strains possessed three mutations: 53D, 100I, 313V. The 53D mutation was reported to be lost when pandemic-origin NP was reintroduced in swine, and this loss was a sign of adaptation to swine [33]. In all the swIAVs, the 313V mutation was present. 

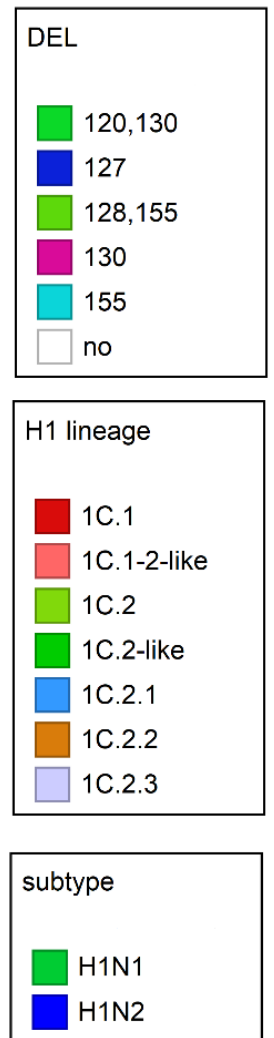
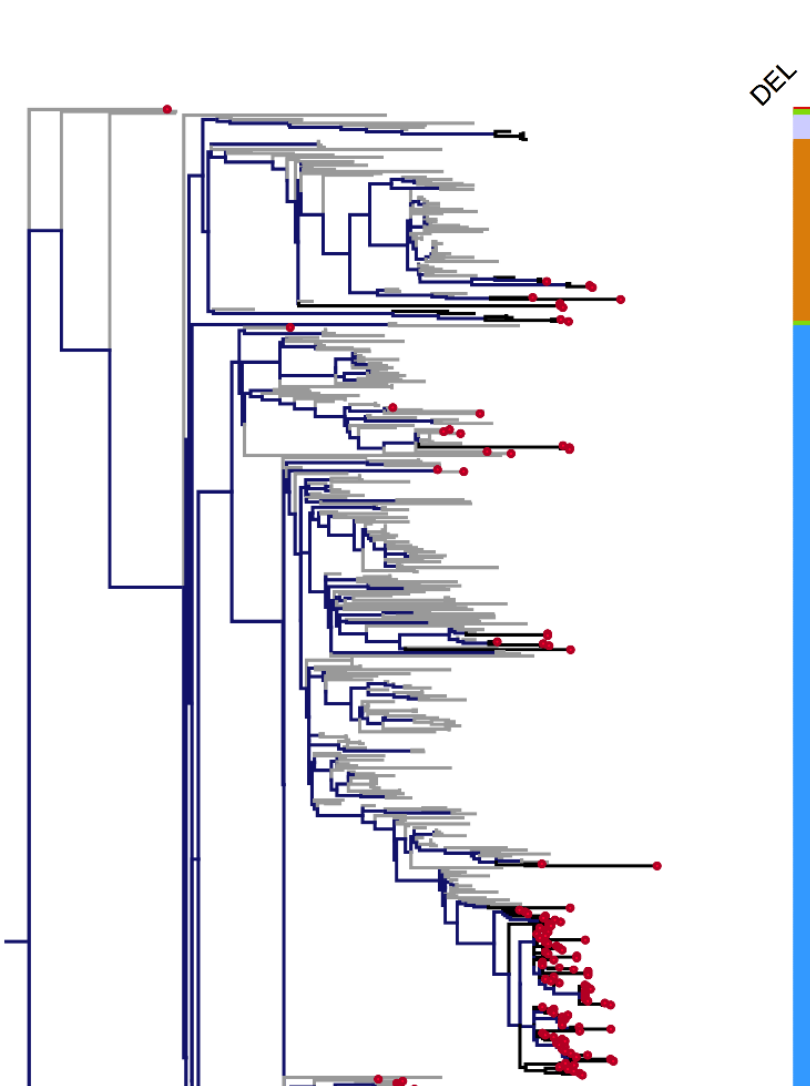

ए人
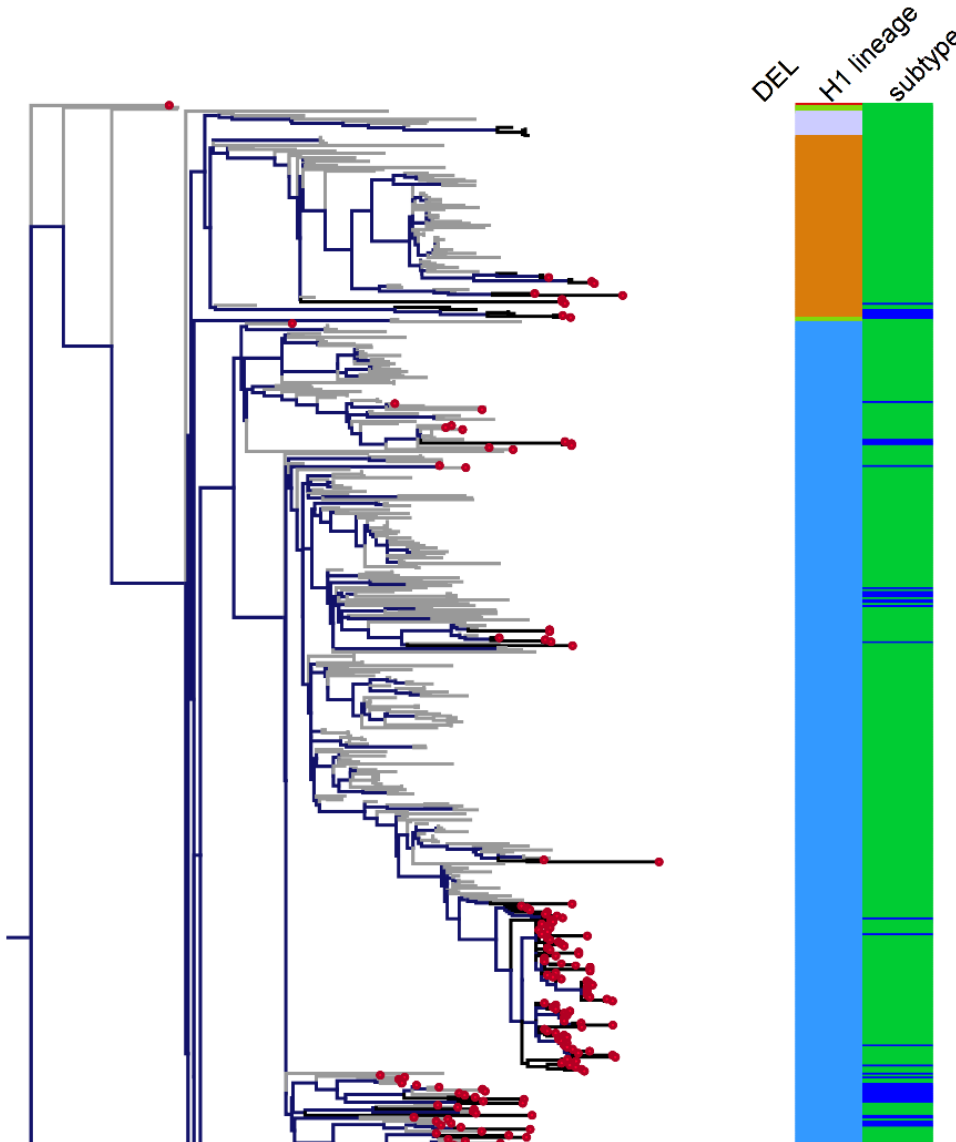


\section{Discussion}

The detection of swIAV subtypes in Italy between 2017 and 2020 showed an evolving situation that deserves continuous monitoring. H1avN1 and H1N2 were the most frequently detected subtypes in Italian swine farms. In 2020, we observed a decreased circulation of H3N2 virus strains and an increased detection of H1-1A viruses accompanied by an increased variability among HA-1A genotypes (Figure 1). We demonstrated the circulation in Italy of three HA-1A3.3.2 sub-clusters: $a$ and b (both swine-adapted) and $c$, seasonal human-derived. In particular, strains belonging to cluster $a$ were shown to be new strains circulating in the country of previously unreported genotypes, detected in eleven farms. The HA and NA genes of these strains clustered with human-derived swine H1-1AN2 strains detected in Denmark and Germany since 2013 (so-called Hu-L strains [18]) and with the H1N1 recently identified in Germany and Denmark, respectively, suggesting they could be the product of reassortments of viruses introduced by pigs imported from central and northern Europe. These reassortant viruses showed different combinations of internal genes (pdm09 and avian-origin) and have been demonstrated to be antigenically different to the previously circulating HA-1A in strains Italy (Table 5). The fitness of these genotypes, provisionally named genotype 31 and genotype 32 , should be further evaluated. In the first years after the 2009 pandemic, H1N1pdm09 did not replace the H1avN1 strains through farm-to-farm transmission in European and Italian pigs, probably because of their cross-reactivity, which conferred cross-protective immunity to the animals. On the other hand, as previously shown in Germany [16], antigenic variants of HA-1A strains (e.g., Papenburg/2010-like or Wachtum/2014-like viruses) could spread with persistent infections in pigs.

The H1N2 subtype was confirmed to be the most variable subtype due to the circulation in Italy of six lineages of $\mathrm{H} 1$ gene (1C.2, 1C.2.1, 1C.2.2, 1B.1.2.1, 1B.1.2.2, 1A.3.3.2) in combination with three N2 lineages (it-N2, N2g, N2s) and pandemic- or avian-origin internal genes. During the study period, eighteen H1N2 genotypes were detected. The genotype F (1B.1.2.2-itN2) was the most prevalent strain circulating among the Italian farms $(38.6 \%)$, swine-endemic Italian H1N2 remaining the most well-adapted. Moreover, the reassortant avian HA-1C.2-N2g strains, probably introduced with live animals (growing pigs and gilts of parental lines) from countries of central/northern Europe (Germany and Denmark), were frequently detected (Table 3, Figure 6). In particular, the high number of combinations of HA-1C genes with different lineages of NA (both N1 and N2 genes) enhanced variability, showing the particular fitness of these reassortant strains to the pig population. This variability was increased by the detection of new variants of HA-1C.2, with deletions in the receptor binding site region and with different antigenic properties that need to be investigated and monitored in the future. The finding, in public sequence databases, of swIAV Danish sequences clustering with the Italian deleted HA-1C.2 strains with deletion $\Delta 127, \Delta 130$, and $\Delta 120,130$ supported the hypothesis of the introduction in Italy of these variants through the importation of live animals. The detection of these variants suggests the need to update $\mathrm{HA}-1 \mathrm{C}$ nomenclature, since many strains, grouping in different sub-clusters, have been provisionally categorized in lineage 1C.2.

Italy imports 50,000 tons of live animals per year (data 2020), mainly from Denmark, the Netherlands, and Germany [37], with an irrelevant role as a swine exporter. The circulation of endemic viruses and the continuous introductions of different viral strains from central and northern Europe makes Italy an important hotspot for the emergence of new genotypes unique to this area. As a consequence, distinct genotype frequencies and genetic variability distinguish Italy from other European countries [6,14,16,18,20,33].

The evidence of the circulation of pandemic-origin genes adapted to swine and the detection of MxA-resistance mutations in NP genes of avian and pandemic origin in the Italian strains analyzed in this study confirmed the significance of the role of swine as an intermediate host. The study's results highlight the importance of systematic surveillance against IVs in the swine population, which must be constantly updated in order to be able to dynamically control the viral hypervariability. Such surveillance is essential in order 
to have an early warning system toward the next potential pandemic $[20,33]$. Moreover, the cocirculation of antigenically variant viruses of each of the H1N1 and H1N2 subtypes needs to be carefully considered using reference viral strains with antibody screening tests such as $\mathrm{HI}$ testing from pig samples.

Supplementary Materials: The following are available online at https://www.mdpi.com/article/10 .3390/v14010047/s1: Figure S1: Phylogenetic tree of N2 sequences. Supplementary File S2: dataset of sequences used in this study. Figure S3: Phylogenetic tree of H1 sequences.

Author Contributions: Conceptualization, C.C.; methodology, L.B., S.F., R.M., I.Z., V.G., I.C. and L.C.; formal analysis, C.C., A.M. and A.F.; investigation, A.P., A.M., M.S.B., C.T. and G.L.A.; writingoriginal draft preparation, C.C.; writing-review and editing, C.C., A.P., A.M., S.F., M.S.B., A.F., L.C., C.T. and A.L. All authors have read and agreed to the published version of the manuscript.

Funding: This research was funded by Italian Ministry of Health "Ricerca corrente", grant number IZSLER PRC2018009 and IZSVe RC 15/18.

Institutional Review Board Statement: Ethical review and approval were waived for this study as the samples were obtained during passive surveillance.

Informed Consent Statement: Not applicable.

Data Availability Statement: The sequences of the strains of this study are available in Genbank, accession numbers: MW220195 -MW220833_2017, MW170386-MW171247, MW169476- MW170361, MW244100-MW244371, MW621504-MW621857, MZ404272-MZ404287, MZ483984-MZ484071, MZ477531-MZ477743, MZ541572-MZ541601, MZ542323. The sequences dataset used in this study are available in Supplementary File S2.

Conflicts of Interest: The authors declare no conflict of interest.

\section{References}

1. Webster, R.G.; Bean, W.J.; Gorman, O.T.; Chambers, T.M.; Kawaoka, Y. Evolution and ecology of influenza A viruses. Microbiol. Rev. 1992, 56, 152-179. [CrossRef]

2. Nelli, R.K.; Kuchipudi, S.V.; White, G.A.; Perez, B.B.; Dunham, S.P.; Chang, K.C. Comparative distribution of human and avian type sialic acid influenza receptors in the pig. BMC Vet. Res. 2010, 6, 4. [CrossRef] [PubMed]

3. Mena, I.; Nelson, M.I.; Quezada-Monroy, F.; Dutta, J.; Cortes-Fernández, R.; Lara-Puente, J.H.; Castro-Peralta, F.; Cunha, L.F.; Trovão, N.S.; Lozano-Dubernard, B.; et al. Origins of the 2009 H1N1 influenza pandemic in swine in Mexico. eLife 2016, 5, e16777. [CrossRef] [PubMed]

4. Zell, R.; Scholtissek, C.; Ludwig, S. Genetics, Evolution, and the Zoonotic Capacity of European Swine Influenza Viruses. Swine Influenza 2013, 370, 29-55.

5. Watson, S.J.; Langat, P.; Reid, S.M.; Lam, T.T.; Cotten, M.; Kelly, M.; Van Reeth, K.; Qiu, Y.; Simon, G.; Bonin, E.; et al. Molecular Epidemiology and Evolution of Influenza Viruses Circulating within European Swine between 2009 and 2013. J. Virol. 2015, 89, 9920-9931. [CrossRef] [PubMed]

6. Henritzi, D.; Petric, P.P.; Lewis, N.S.; Graaf, A.; Pessia, A.; Starick, E.; Breithaupt, A.; Strebelow, G.; Luttermann, C.; Parker, L.M.K.; et al. Surveillance of European Domestic Pig Populations Identifies an Emerging Reservoir of Potentially Zoonotic Swine Influenza A Viruses. Cell Host Microbe 2020, 28, 614-627. [CrossRef] [PubMed]

7. $\quad$ Lewis, N.S.; Russell, C.A.; Langat, P.; Anderson, T.K.; Berger, K.; Bielejec, F.; Burke, D.F.; Dudas, G.; Fonville, J.M.; Fouchier, R.A.; et al. The global antigenic diversity of swine influenza A viruses. eLife 2016, 5, e12217. [CrossRef]

8. Anderson, T.K.; Macken, C.A.; Lewis, N.S.; Scheuermann, R.H.; Van Reeth, K.; Brown, I.H.; Swenson, S.L.; Simon, G.; Saito, T.; Berhane, Y.; et al. A Phylogeny-Based Global Nomenclature System and Automated Annotation Tool for H1 Hemagglutinin Genes from Swine Influenza A Viruses. mSphere 2016, 1, e00275-16. [CrossRef] [PubMed]

9. Chastagner, A.; Herve, S.; Queguiner, S.; Hirchaud, E.; Lucas, P.; Gorin, S.; Beven, V.; Barbier, N.; Deblanc, C.; Blanchard, Y.; et al. Genetic and Antigenic Evolution of European Swine Influenza A Viruses of HA-1C (Avian-like) and HA-1B (Human-like) Lineages in France from 2000 to 2018. Viruses 2020, 12, 1304. [CrossRef] [PubMed]

10. Trebbien, R.; Bragstad, K.; Larsen, L.E.; Nielsen, J.; Botner, A.; Heegaard, P.M.; Fomsgaard, A.; Viuff, B.; Hjulsager, C.K. Genetic and biological characterisation of an avian-like H1N2 swine influenza virus generated by reassortment of circulating avian-like H1N1 and H3N2 subtypes in Denmark. Virol. J. 2013, 10, 290. [CrossRef]

11. Krog, J.S.; Hjulsager, C.K.; Larsen, M.A.; Larsen, L.E. Triple-reassortant influenza A virus with H3 of human seasonal origin, NA of swine origin, and internal A(H1N1) pandemic 2009 genes is established in Danish pigs. Influenza Other Respir Viruses 2017, 11, 298-303. [CrossRef] 
12. Zell, R.; Groth, M.; Krumbholz, A.; Lange, J.; Philipps, A.; Durrwald, R. Novel reassortant swine H3N2 influenza A viruses in Germany. Sci. Rep. 2020, 10, 14296. [CrossRef]

13. Chastagner, A.; Herve, S.; Bonin, E.; Queguiner, S.; Hirchaud, E.; Henritzi, D.; Beven, V.; Gorin, S.; Barbier, N.; Blanchard, Y.; et al. Spatiotemporal Distribution and Evolution of the A/H1N1 2009 Pandemic Influenza Virus in Pigs in France from 2009 to 2017: Identification of a Potential Swine-Specific Lineage. J. Virol. 2018, 92, e00988-18. [CrossRef]

14. Zell, R.; Groth, M.; Krumbholz, A.; Lange, J.; Philipps, A.; Durrwald, R. Displacement of the Gent/1999 human-like swine H1N2 influenza A virus lineage by novel H1N2 reassortants in Germany. Arch. Virol. 2020, 165, 55-67. [CrossRef]

15. Harder, T.C.; Grosse Beilage, E.; Lange, E.; Meiners, C.; Dohring, S.; Pesch, S.; Noe, T.; Grund, C.; Beer, M.; Starick, E. Expanded cocirculation of stable subtypes, emerging lineages, and new sporadic reassortants of porcine influenza viruses in swine populations in Northwest Germany. J. Virol. 2013, 87, 10460-10476. [CrossRef] [PubMed]

16. Zell, R.; Groth, M.; Krumbholz, A.; Lange, J.; Philipps, A.; Durrwald, R. Cocirculation of Swine H1N1 Influenza A Virus Lineages in Germany. Viruses 2020, 12, 762. [CrossRef]

17. Chepkwony, S.; Parys, A.; Vandoorn, E.; Stadejek, W.; Xie, J.; King, J.; Graaf, A.; Pohlmann, A.; Beer, M.; Harder, T.; et al. Genetic and antigenic evolution of H1 swine influenza A viruses isolated in Belgium and the Netherlands from 2014 through 2019. Sci. Rep. 2021, 11, 11276. [CrossRef] [PubMed]

18. Ryt-Hansen, P.; Krog, J.S.; Breum, S.O.; Hjulsager, C.K.; Pedersen, A.G.; Trebbien, R.; Larsen, L.E. Co-circulation of multiple influenza A reassortants in swine harboring genes from seasonal human and swine influenza viruses. eLife 2021, 10, e60940. [CrossRef] [PubMed]

19. Chiapponi, C.; Ebranati, E.; Pariani, E.; Faccini, S.; Luppi, A.; Baioni, L.; Manfredi, R.; Carta, V.; Merenda, M.; Affanni, P.; et al Genetic analysis of human and swine influenza A viruses isolated in Northern Italy during 2010-2015. Zoonoses Public Health 2017, 65, 114-123. [CrossRef] [PubMed]

20. Dornfeld, D.; Petric, P.P.; Hassan, E.; Zell, R.; Schwemmle, M. Eurasian Avian-like Swine Influenza A Viruses Escape Human MxA Restriction through Distinct Mutations in Their Nucleoprotein. J. Virol. 2019, 93, e00997-18. [CrossRef]

21. Moreno, A.; Gabanelli, E.; Sozzi, E.; Lelli, D.; Chiapponi, C.; Ciccozzi, M.; Zehender, G.; Cordioli, P. Different evolutionary trends of swine H1N2 influenza viruses in Italy compared to European viruses. Vet. Res. 2013, 44, 112. [CrossRef]

22. Slomka, M.J.; Densham, A.L.; Coward, V.J.; Essen, S.; Brookes, S.M.; Irvine, R.M.; Spackman, E.; Ridgeon, J.; Gardner, R.; Hanna, A.; et al. Real time reverse transcription (RRT)-polymerase chain reaction (PCR) methods for detection of pandemic (H1N1) 2009 influenza virus and European swine influenza A virus infections in pigs. Influenza Other Respir. Viruses 2010, 4, $277-293$. [CrossRef]

23. Hoffmann, E.; Stech, J.; Guan, Y.; Webster, R.G.; Perez, D.R. Universal primer set for the full-length amplification of all influenza A viruses. Arch. Virol. 2001, 146, 2275-2289. [CrossRef] [PubMed]

24. Hoffmann, B.; Harder, T.; Lange, E.; Kalthoff, D.; Reimann, I.; Grund, C.; Oehme, R.; Vahlenkamp, T.W.; Beer, M. New real-time reverse transcriptase polymerase chain reactions facilitate detection and differentiation of novel A/H1N1 influenza virus in porcine and human samples. Berl. Munch. Tierarztl. Wochenschr. 2010, 123, 286-292. [PubMed]

25. Henritzi, D.; Zhao, N.; Starick, E.; Simon, G.; Krog, J.S.; Larsen, L.E.; Reid, S.M.; Brown, I.H.; Chiapponi, C.; Foni, E.; et al. Rapid detection and subtyping of European swine influenza viruses in porcine clinical samples by haemagglutinin- and neuraminidasespecific tetra- and triplex real-time RT-PCRs. Influenza Other Respir. Viruses 2016, 10, 504-517. [CrossRef]

26. Chiapponi, C.; Zanni, I.; Garbarino, C.; Barigazzi, G.; Foni, E. Comparison of the usefulness of the CACO-2 cell line with standard substrates for isolation of swine influenza A viruses. J. Virol. Methods 2010, 163, 162-165. [CrossRef]

27. OIE. Manual of Diagnostic Tests and Vaccines for Terrestrial Animals Part 2, Section 3.8, Chapter 3.8.7, 2018th ed.; World Organization for Animal Health: Paris, France, 2018.

28. Lycett, S.J.; Baillie, G.; Coulter, E.; Bhatt, S.; Kellam, P.; McCauley, J.W.; Wood, J.L.; Brown, I.H.; Pybus, O.G.; Leigh Brown, A.J.; et al. Estimating reassortment rates in co-circulating Eurasian swine influenza viruses. J. Gen. Virol. 2012, 93, 2326-2336. [CrossRef] [PubMed]

29. Kumar, S.; Stecher, G.; Li, M.; Knyaz, C.; Tamura, K. MEGA X: Molecular Evolutionary Genetics Analysis across Computing Platforms. Mol. Biol. Evol. 2018, 35, 1547-1549. [CrossRef]

30. Minh, B.Q.; Schmidt, H.A.; Chernomor, O.; Schrempf, D.; Woodhams, M.D.; von Haeseler, A.; Lanfear, R. IQ-TREE 2: New Models and Efficient Methods for Phylogenetic Inference in the Genomic Era. Mol. Biol. Evol. 2020, 37, 1530-1534. [CrossRef] [PubMed]

31. Hoang, D.T.; Chernomor, O.; von Haeseler, A.; Minh, B.Q.; Vinh, L.S. UFBoot2: Improving the Ultrafast Bootstrap Approximation. Mol. Biol. Evol. 2018, 35, 518-522. [CrossRef] [PubMed]

32. Kalyaanamoorthy, S.; Minh, B.Q.; Wong, T.K.F.; von Haeseler, A.; Jermiin, L.S. ModelFinder: Fast model selection for accurate phylogenetic estimates. Nat. Methods 2017, 14, 587-589. [CrossRef]

33. Manz, B.; Dornfeld, D.; Gotz, V.; Zell, R.; Zimmermann, P.; Haller, O.; Kochs, G.; Schwemmle, M. Pandemic influenza A viruses escape from restriction by human MxA through adaptive mutations in the nucleoprotein. PLoS Pathog. 2013, 9, e1003279. [CrossRef] [PubMed]

34. Liang, H.; Lam, T.T.; Fan, X.; Chen, X.; Zeng, Y.; Zhou, J.; Duan, L.; Tse, M.; Chan, C.H.; Li, L.; et al. Expansion of genotypic diversity and establishment of $2009 \mathrm{H} 1 \mathrm{~N} 1$ pandemic-origin internal genes in pigs in China. J. Virol. 2014, 88, 10864-10874. [CrossRef] [PubMed] 
35. Sriwilaijaroen, N.; Suzuki, Y. Molecular basis of the structure and function of H1 hemagglutinin of influenza virus. Proc. Jpn. Acad. Ser. B Phys. Biol. Sci. 2012, 88, 226-249. [CrossRef] [PubMed]

36. Burke, D.F.; Smith, D.J. A recommended numbering scheme for influenza A HA subtypes. PLoS ONE 2014, 9, e112302. [CrossRef] [PubMed]

37. Trade Map. Available online: https:/ / www.trademap.org/ (accessed on 30 June 2021). 